\title{
Knowledge and Assessment of Hemophilia Clinical Practice Approaches Among Dentists
}

\author{
Sara Abdu ${ }^{1}$, Ahmed Osama ${ }^{1}$, Mohammed Abdulmajeed ${ }^{1}$, Manar Ali ${ }^{1}$ and Amel Eltayeb ${ }^{2 *}$ \\ ${ }^{1}$ Faculty of Dentistry, Nile University, Khartoum, Sudan \\ ${ }^{2}$ Department of Oral and Maxillofacial Surgery, Faculty of Dentistry, Nile University, Khartoum, Sudan
}

Submission: April 28, 2020; Published: May 18, 2020

*Corresponding author: Amel Eltayeb, Department of Oral and Maxillofacial surgery, Faculty of Dentistry, Nile University, Khartoum, Sudan

Abstract

Background and Aims: Most hemophilic patients with dental problems refuse to receive treatments for the fear of bleeding during the procedures. The aim of this study was to evaluate and assess the dentists' knowledge about hemophilia, related drugs, management and complication arise in such patient.

Materials and Methods: This cross-sectional study was carried out on 188 dentists at Khartoum Teaching Dental Hospital. A selfadministered structured questionnaire was used to collect data from dentists which included: Socio demographic characteristics such as age, gender, qualification and the respondents' knowledge of the clinical features of hemophilia, laboratory diagnosis, dental care and treatment and complications.

Results: The response rate was $100 \%$. There were 188 respondents comprising 84 (44.7\%) males and 104 (55.3\%) females. Most 129 $(68.6 \%)$ of the respondents were in the age group 21-26 years and the lowest number of respondents were in the age group 37-46 years. The majority of respondents were BDs holders $75.5 \%$. Of all participants, $87.2 \%$ were aware that hemophilia is hereditary blood disorder while $42 \%$ agreed that males are predominantly affected. Regarding the treatment, $87.2 \%$ of the participants agreed that replacement of factor VIII and factor IX is required before the major surgery in hemophilic patient. A statistically significant correlation between dentists' knowledge and age and title was revealed in this study P-value (0.00). Fifty-nine (31.4\%) participants will prefer not to treat a hemophilic patient for any dental procedure.

Conclusion: Continuous education programs about hemophilia and expressing the importance of knowing about this common disease and it is related complication is very important to enrich our information about this disease.

\section{Introduction}

Hemophilia is an inherited coagulation disorder involving a deficiency of factor VIII (in hemophilia A) or factor IX (in hemophilia B) [1]. Hemophilia A is inherited as an autosomal $\mathrm{X}$-linked recessive trait; therefore, the disease mainly affects males $[2,3]$. Hemophilia has an estimated frequency of approximately one in 10,000 births. A recent Estimations based on the World Federation of Hemophilia annual global surveys indicate that the number of people with hemophilia in the world is approximately 400,000 [1]. Hemophilia A is more common than hemophilia B, representing $80-85 \%$ of the total hemophilia population [2]. There are no basic differences in the oral health problems of the hemophiliac and those of the average individual; however, optimal dental health is more of a necessity for the hemophiliac in view of the problems posed by dental surgery. Therefore, it is reasonable to expect that today's dental health professionals can and should provide the care so desperately needed by the hemop

\section{Material and Methods}

A cross-sectional descriptive study was done at Khartoum Teaching Dental Hospital (KTDH) from October to November 2019. KTDH is a tertiary hospital in Khartoum-capital of Sudan, it is also the main training center for postgraduate dentists from all over Sudan. A self-administered structured questionnaire was used to collect data from dentists working at KTDH including: Socio demographic characteristics such as age, gender, qualification and the specialty and the respondents' knowledge of the clinical features of hemophilia, laboratory diagnosis, dental care and treatment and complications. Obtained information was imputed into computer and statistical analysis was done using Statistical Package for Social Sciences (SPSS) software version 23. Ethical approval will be obtained from the research committee of Nile University also a written consent will be obtained from the participant. 


\section{Advances in Dentistry \& Oral Health}

\section{Results}

The response rate was $100 \%$. There were 188 respondents comprising $84(44.7 \%)$ males and 104 (55.3\%) females. Most $129(68.6 \%)$ of the respondents were in the age group 21-26 years and the lowest number of respondents were in the age group 37-46 years. The majority of respondents were BDs holders 75.5\% (Table 1). The questionnaire contained 19 questions about hemophilia, the choices of all questions were yes, no and I do not know. Participants responses are shown in Table 2. One hundred and sixty-four $(87.2 \% .8 \%)$ of the respondents were aware that hemophilia is hereditary blood disorder while 79 (42\%) agreed that males are predominantly affected. When dentists asked if the spontaneous gingival bleeding is one of the common oral manifestation of hemophilia, 147 (78.2\%) responded by yes and 12 (6.4\%) said they do not know. One hundred and sixty-four $(87.2 \%)$ of the participants agreed that replacement of factor VIII and factor IX is required before the major surgery in hemophilic

Table 1: Demographic Characteristics of Respondents.

\begin{tabular}{|c|c|c|c|}
\hline characteristics & & Frequency & $\%$ \\
\hline \multicolumn{4}{|l|}{ Age } \\
\hline & 21-26 year & 129 & $68.6 \%$ \\
\hline & 27-36 year & 54 & $28.7 \%$ \\
\hline & $37-46$ year & 5 & $2.7 \%$ \\
\hline \multicolumn{4}{|l|}{ Gender } \\
\hline & Male & 84 & $44.7 \%$ \\
\hline & Female & 104 & $55.3 \%$ \\
\hline \multicolumn{4}{|l|}{ Qualification } \\
\hline & BDs & 142 & 75.5 \\
\hline & MSc & 17 & 9.0 \\
\hline & $\mathrm{PhD} / \mathrm{MD}$ & 23 & 12.2 \\
\hline & others & 6 & 3.2 \\
\hline \multicolumn{4}{|l|}{ Profession } \\
\hline & Interns & 119 & 63.3 \\
\hline & Medical officer & 33 & 17.6 \\
\hline & Resident & 30 & 16.0 \\
\hline & specialist & 6 & 3.2 \\
\hline Total & & 188 & $100 \%$ \\
\hline
\end{tabular}

Table 2: Respondents' Knowledge of hemophilia patients, laboratory diagnosis and treatment.

\begin{tabular}{|c|c|c|c|}
\hline Question & Yes & No & I don't know \\
\hline 1. The hemophilia is hereditary blood clotting disorder? & $\begin{array}{c}164 \\
87.2 \%\end{array}$ & $\begin{array}{c}19 \\
10.1 \%\end{array}$ & $\begin{array}{c}5 \\
2.7 \%\end{array}$ \\
\hline 2. The cause of hemophilia is unknown & $5227.6 \%$ & $\begin{array}{l}124 \\
66 \%\end{array}$ & $\begin{array}{c}12 \\
6.4 \%\end{array}$ \\
\hline 3. Hemophilia is the most common hemorrhagic diathesis? & $\begin{array}{c}119 \\
63.3 \%\end{array}$ & $\begin{array}{c}33 \\
17.6 \%\end{array}$ & $\begin{array}{c}36 \\
19.1 \%\end{array}$ \\
\hline $\begin{array}{l}\text { 4. Is it possible for a person to be born with hemophilia if his parents do not have } \\
\text { the disorder? }\end{array}$ & $\begin{array}{c}120 \\
63.8 \%\end{array}$ & $\begin{array}{c}46 \\
24.5 \%\end{array}$ & $\begin{array}{c}22 \\
11.7 \%\end{array}$ \\
\hline
\end{tabular}

patient.

When the participants were asked about their experience with any treatment protocol of hemophilic patients presenting to dental clinic, one hundred and thirty (69.1\%) knew about such a protocol but only sixty-nine participants (36.7\%) have previous experience with such protocol. Fifty-nine (31.4\%) participants will prefer not to treat a hemophilic patient for any dental procedure, 158 participants (84\%) will prefer to refer the hemophilic patient to a medical doctor for pre-operative consultation and 153 participants (81.4\%) will ask for a consent for treating such patients (Table 3). A correlation between dentists' knowledge and age and title was studied and it was found to be statistically significant P-value (0.00). of all the participant, $70 \%$ of the residents had good knowledge in comparison to the newly graduate interns (26.9\%) and older dentists had more knowledge than younger one. Moreover, correlation between knowledge and qualification of the participants was found to be statistically significant P-value (0.041), PhD holder were more knowledgeable. 


\begin{tabular}{|c|c|c|c|}
\hline 5. Hemophilia is more in female than male? & $\begin{array}{c}64 \\
34 \% \\
\end{array}$ & $\begin{array}{c}79 \\
42 \% \\
\end{array}$ & $\begin{array}{c}45 \\
24 \% \\
\end{array}$ \\
\hline 6. There is no cure for hemophilia? & $\begin{array}{c}100 \\
53.2 \%\end{array}$ & $\begin{array}{c}60 \\
31.9 \%\end{array}$ & $\begin{array}{c}28 \\
14.9 \%\end{array}$ \\
\hline 7. In the minor or major surgery, the INR should be less than 3.0 ? & $\begin{array}{c}132 \\
70.2 \%\end{array}$ & $\begin{array}{c}25 \\
13.3 \%\end{array}$ & $\begin{array}{c}31 \\
16.5 \%\end{array}$ \\
\hline 8. The INR is the only investigation for hemophilia? & $\begin{array}{c}21 \\
11.2 \%\end{array}$ & $\begin{array}{c}142 \\
75.5 \%\end{array}$ & $\begin{array}{c}25 \\
13.3 \%\end{array}$ \\
\hline $\begin{array}{l}\text { 9. In patient with hemophilia with multiples extraction the choice is extracted one } \\
\text { or two teeth only? }\end{array}$ & $\begin{array}{c}111 \\
59 \%\end{array}$ & $\begin{array}{c}34 \\
18.1 \%\end{array}$ & $\begin{array}{c}43 \\
22.9 \%\end{array}$ \\
\hline $\begin{array}{l}\text { 10. Dental pain in patient with hemophilia usually can be controlled by acetylsali- } \\
\text { cylic acid? }\end{array}$ & $\begin{array}{c}50 \\
26.6 \%\end{array}$ & $\begin{array}{c}63 \\
33.5 \%\end{array}$ & $\begin{array}{c}75 \\
39.3 \%\end{array}$ \\
\hline $\begin{array}{l}\text { 11. The most oral manifestation finding in patient with hemophilia is spontaneous } \\
\text { gingival Bleeding? }\end{array}$ & $\begin{array}{c}147 \\
78.2 \%\end{array}$ & $\begin{array}{c}29 \\
15.4 \%\end{array}$ & $\begin{array}{c}12 \\
6.4 \%\end{array}$ \\
\hline $\begin{array}{l}\text { 12. Replacement of factor VIII and factor IX and fresh frozen plasma is required } \\
\text { before the Major surgery? }\end{array}$ & $\begin{array}{c}164 \\
87.2 \%\end{array}$ & $\begin{array}{c}8 \\
4.3 \%\end{array}$ & $\begin{array}{l}16 \\
8.5 \%\end{array}$ \\
\hline 13. Classification of hemophilia based on plasma procoagulant level? & $\begin{array}{c}65 \\
34.6 \%\end{array}$ & $\begin{array}{c}37 \\
19.7 \%\end{array}$ & $\begin{array}{c}86 \\
45.7 \%\end{array}$ \\
\hline
\end{tabular}

Table 3: Shows participants experience with treatment protocols of hemophilic patients.

\begin{tabular}{|c|c|c|c|}
\hline Question & Yes & No & I don't know \\
\hline 1. Do you know about protocol management of patient with hemophilia? & $\begin{array}{c}130 \\
69.1 \%\end{array}$ & $\begin{array}{c}22 \\
11.7 \%\end{array}$ & $\begin{array}{c}36 \\
19.1 \%\end{array}$ \\
\hline 2. Have you ever treated a hemophilic patient using a protocol? & $\begin{array}{c}69 \\
36.7 \%\end{array}$ & $\begin{array}{c}104 \\
55.3 \%\end{array}$ & $\begin{array}{l}15 \\
8 \%\end{array}$ \\
\hline 3. Will you consult a medical doctor before treating hemophilic patient? & $\begin{array}{l}158 \\
84 \%\end{array}$ & $\begin{array}{c}24 \\
12.8 \%\end{array}$ & $\begin{array}{c}6 \\
3.2 \%\end{array}$ \\
\hline 4. Would you personally perform dental procedure in hemophilic patient? & $\begin{array}{c}119 \\
63.3 \%\end{array}$ & $\begin{array}{c}59 \\
31.4 \%\end{array}$ & $\begin{array}{c}10 \\
5.3 \%\end{array}$ \\
\hline 5. Will you prefer to refer the hemophilic patient to another dentist/specialist? & $\begin{array}{c}77 \\
41 \%\end{array}$ & $\begin{array}{c}101 \\
53.7 \%\end{array}$ & $\begin{array}{c}10 \\
5.3 \%\end{array}$ \\
\hline $\begin{array}{l}\text { 6. Will you refer patients to a physician for consent regarding carrying dental } \\
\text { procedures? }\end{array}$ & $\begin{array}{c}153 \\
81.4 \%\end{array}$ & $\begin{array}{c}28 \\
14.9 \%\end{array}$ & $\begin{array}{l}7 \\
3.7 \%\end{array}$ \\
\hline
\end{tabular}

\section{Discussion}

Hemophilia remains a lifelong non-curative chronic condition and is associated with significant morbidity [7]. The affected individual frequently experiences spontaneous and prolonged bleeding from cuts or injuries or post-surgery or dental extraction [8]. This study assessed the basic knowledge of the clinical features, laboratory diagnosis as well as care and treatment of hemophiliac patient among dentists at KTDH. This study targeted different groups composed of newly graduate dentists(interns), (63.3\%), medical officers $(17.6 \%)$, residents $(16 \%)$ and specialist (3.2\%). The aim was to know whether these groups gained their information about hemophilia from undergraduate studies or from other different experiences such as internship, or even from lifetime experiences. The study was in Khartoum teaching hospital due to the presence of large number and wide range of the dental field practitioners. The data gathering was done with the use of a questionnaire, making it easier, faster, accessible, and feasible. A Nigerian study by Balogun et al. [9] reported that $96.8 \%$ of the respondents were aware that hemophilia is hereditary while $66.5 \%$ agreed that the males are predominantly affected. Another study by Miller et al. reported more than $80 \%$ were aware of the inheritance pattern of hemophilia. In this study, $87.2 \%$ of the respondents reported hemophilia as hereditary and only $42 \%$ mentioned that males are predominately affected. A study by Novais et al. [10] mentioned that most interviewees had good basic knowledge of treatment of hemophilic patients [10]. In this study, $87.2 \%$ of the respondent agreed that replacement of deficient coagulation factor is the mainstay of management of the hemophiliac. Almost similar result reported in Nigeria where $81.6 \%$ of the respondents reported the replacement treatment [9].

The final result showed there is a relationship between the individual's title, age and experience. A correlation between dentists' knowledge and the profession was studied and it was found to be statistically significant P-value $(0.00)$. Of all 
the participant, $70 \%$ of the residents had good knowledge in comparison to the newly graduate interns (26.9\%). There's some sort of negligible relationship between knowledge and experience after BDS, because most of the individuals were fresh graduates, making them have lesser experience with limited knowledge. Aza Rahman et al. [11] made a previous study in UK, which proved that there is a poor knowledge about hemophilia management and risk assessment in dental chair [11]. Also, another study was made by Balogun et al. [9] Nigeria which showed that the knowledge about hemophilia is also limited and need to be reinforced. In our study: $35.6 \%$ have a good knowledge, $43.1 \%$ have moderate knowledge, while only $21.3 \%$ have a poor knowledge. This knowledge about hemophilia among participants was generally acceptable but we should consider that the fact of the percentage of poor knowledge is not minimal, and even a slight number can affect the entire community.

\section{Conclusion}

Continuous education programs about hemophilia and expressing the importance of knowing about this common disease and it is related complication is very important to enrich our information about this disease. Knowledge is the key, and it's very impactful in applying prevention programs to help reduce complication and improving the quality of life.

\section{References}

1. JJNL P (2015) Bleeding and clotting disorders. In: Glick M, editor. Burket's Oral Medicine, $12^{\text {th }}$ Edition. Buffalo New York: People's Medical Publishing House-USA pp. 463-88.

2. Barr RD, Saleh M, Furlong W, Horsman J, Sek J, et al. (2002) Health status and health-related quality of life associated with hemophilia.
American journal of hematology 71(3): 152-160.

3. Di Michele D, Gibb C, Lefkowitz J, Ni Q Gerber A (2014) Severe and moderate haemophilia A and B in US females. Haemophilia 20(2): e136-e43.

4. Naveen Kumar J, Anil Kumar R, Varadarajan R, Sharma N (2007) Specialty dentistry for the hemophiliac: Is there a protocol in place? Indian Journal of Dental Research 18(2): 48-54.

5. Israels S, Schwetz N, Boyar R, McNicol A (2006) Bleeding disorders: characterization, dental considerations and management. Journal of the Canadian Dental Association 72(9): 827.

6. Abrisham M, Tabrizizadeh M, Ghateh A (2009) Knowledge of Oral Hygiene among Hemophilic Patients Referred to Iranian Hemophilia Society. J Dent Res Dent Clin Dent Prospects 3(2): 60-63.

7. Sokal EM, Lombard C, Mazza G (2015) Mesenchymal stem cell treatment for hemophilia: a review of current knowledge. J Thromb Haemost 13(1): S161-S166.

8. Roberts HR, Escoban M, GC W (2006) Hemophilia A and Hemophilia B. In Lichtman AM, Beutler E, Kipps TJ, Seligsohn U,Kaushan K, Prchal TJ, eds) Williams Haematology $7^{\text {th }}$ edition McGraw-Hill Medical Publishing 1867-1874.

9. Balogun T, Agboola M, Onigbinde OO (2018) Haemophilia Knowledge among Health Care Providers in a Tertiary Hospital Lagos, Nigeria 6: 50-150.

10. Novais T, Duclos A, Varin R, Lopez I, Chamouard V (2016) Treatmentrelated knowledge and skills of patients with haemophilia and their informal caregivers. Int J Clin Pharm 38(1): 61-69.

11. Rahman A, Nizarali N, Dougall A, Blanaid D (2019) UK hemophilia treaters' knowledge of risk assessment for prolonged bleeding associated with dental procedures. Special Care in Dentistry 39(2): 173-179. 